\title{
VIRTUAL REALITY: A TOOL FOR CARTOGRAPHIC VISUALIZATION
}

\author{
J. A. Quaye-Ballard \\ Department of Geomatic Engineering, \\ Faulty of Civil and Geomatic Engineering, \\ Kwame Nkrumah University of Science and Technology (KNUST), Kumasi, Ghana
}

\begin{abstract}
Visualization methods in the analysis of geographical datasets are based on static models, which restrict the visual analysis capabilities. The use of virtual reality, which is a three-dimensional (3D) perspective, gives the user the ability to change viewpoints and models dynamically overcomes the static limitations of two-dimensional (2D) views. Based on this, the paper highlights the importance, characteristic and classification of Virtual Reality as a tool in data visualization. The paper also outlines real life applications of Virtual Reality as a means of visualization. The distinction between Virtual Reality and Cartography is also presented. This paper also attempts to outline the Virtual Reality Modelling Language (VRML), which is a scene description language for developing Virtual Reality.
\end{abstract}

Keywords: Visualization, Virtual reality, Virtual Reality Modelling Language (VRML), Cartography

\section{INTRODUCTION}

Virtual reality has several terminologies such as virtual world and virtual environment but this paper adopts virtual reality. Virtual reality could be said to be the result from interaction between the cognitive level of human beings, usually designated as mental maps, and the visual and audible images produced by computers (Jacobson, 1994). Jacobson defined virtual reality as a space deliberately designed by man, representing real or abstract spaces in which objects exists.

Burdea and Coiffet (1994) indicated that, virtual reality facilitates human-computer interaction by use of three-dimensional representation and direct manipulation of virtual objects. These representations can be seen as plane images, and as two and half dimension $\left(2 \frac{1}{2} \mathrm{D}\right)$ models in a conventional monitor or in a truly three-dimensional (3D) space in an immersive environment. Views in $2 \frac{1}{2} \mathrm{D}$ are like bird's eye view, where the user looks down on the model as if it is a three-dimensional view but the user is not immersed within the model.

Many aspects exist when one talks about virtual reality, as to whether it is being designed or constructed for a single user or multiple users and how the user can interact with the environment. 
Definitions and description of Virtual Reality

A concise definition of virtual reality is given by Fisher and Unwin (2002) as 'the ability of the user of a constructed view of a limited digitallyencoded information domain to change their view in three dimension causing update of the view presented to any viewer (the user)'. The definition gives a brief summary of the essence of all visualizations that can be called virtual reality. Thus, applying the definition, the users would have the capability of changing the viewing positions of objects on the computer.

Virtual Reality can be defined from different perspectives, for instance, considering the situation where the user is immersed in the computergenerated environment. Virtual reality could be defined from the point of view of the technological tools being employed, for example, the use of head mounted display units and motion-tracking gloves. Virtual reality could also be defined from the psychological perspective where technology does not come into play, rather the state produced in the users' minds that could occupy their awareness in a way similar to that of real environments (Keppell and Macpherson, 1997).

According to Fällman et al (1999), the best way to define virtual reality is to centre on the user and look at the style of interaction that takes place between the user and the computer generatedenvironment. Fällman further illustrated that, users manipulate what is perceived to be real objects in the same manner as they would manipulate in the real world.

Online Dictionary.com (2006) defined virtual reality as 'a computer simulation of a real or imaginary system that enables a user to perform operations on the simulated system and shows the effects in real time'. The computer simulation involves hypothetical three-dimensional visual world created by the computer. Virtual reality can be viewed from the perspective of humancomputer interface (Brodlie et al, 2002). The authors described virtual reality as a tool or approach that can be used to undertake investiga- tions or present information in a new and challenging ways.

\section{Importance of Virtual Reality}

The use of visualization methods in the analysis of geo-referenced data is based on static models, which restricts the visual analysis capabilities. Thus, the use of virtual reality, which gives the user the ability to change viewpoints and models dynamically, can help overcome the static limitations of analysing and visualizing geo-referenced data (Diotin and Kooy, 1995). Fairbairn and Parsey (1996) also added that virtual reality is a technique that enables users to move towards a finer emulation of the complexities of the real world. In addition, Baker and Wickens (1992) indicated that virtual reality provides an interactive environment, which is well suited to supporting the interactive presentation of scientific datasets. Virtual reality is an important tool in navigation and object manipulation as well as immersion within the designed application. It facilitates egocentric views in which the display is constructed from the point of view of the user who may be inside the designed application as compared to desktop tools, which generally restricts the user to the outside (termed exocentric view). Virtual reality brings the promise of a much more comprehensive way of visualizing data. The user is within the middle of the plan and can directly interact with the 3D data (Verbree et al, 1999).

All the above indicate the importance of virtual reality for in-depth understanding and analysing of data, be it either geo-referenced or not. Virtual reality is very important in analysing and visualizing scientific data because of the 3D and dynamic characteristics it provides.

\section{Characteristics of Virtual Reality}

Based on the above chosen definition, virtual reality can be characterized by a number of characters. Baker and Wickens (1992) characterized virtual reality according to a number of characters, which contributes to the sense of reality. These are as illustrated below: 
- Virtual views are in three-dimensional perspective. That is, often in stereoscopic, unlike the planar two-dimensional (2D) views commonly used in desktop environments.

- Virtual point-of-view is egocentric, whereby the user is provided with a view of virtual space that matches their physical position and direction of view within the space, allowing the immersion of the user in the virtual world.

- The virtual environment is dynamic rather than static.

The above characteristics can be attributed to the nature of problem at hand, as in designing an effective virtual environment for analysing scientific data and demands a full understanding of the nature of the problem. These characteristics of virtual reality can be used to classify virtual reality under desktop, semi-immersive and fully immersive virtual realities.

\section{Classification of Virtual Reality}

This section discusses on the classification of virtual reality based on the immersion of the user and the S-P-I (Simulation, Presentation and Interaction) model. These two possible methods of classifying are illustrated below:

\section{Classification of Virtual Reality with Respect to Immersion of the User}

With reference to Cronin (1999), there are basically three different kinds of virtual reality classified by the type of immersion that is being provided. These are desktop, semi-immersive and fully immersive virtual realities. In Ogao's (1997) contribution, these classifications can also be based on hardware and interface capabilities. These classifications of virtual reality can also be regarded as a continuum based on the levels of interactions and the real world used to facilitate transformation (Brodlie et al, 2002). These classifications are as follows:

- Desktop Virtual Reality (DVR), which is by far the most common and least expensive form of virtual reality. It typically consists of a standard desktop computer. It is a form of virtual reality which lacks any feelings of immersion on the part of the user.

- Semi-Immersive Virtual Reality, which attempts to give the user a feeling of being at least slightly immersed by the virtual environment. This is often achieved by workbenches and reach-in displays. Ogao (1997) classified this as Transparent Virtual Reality, which uses the real world as backdrop and is seen through the device presenting the spatial information.

- Fully Immersive Virtual Reality, which consists of head mounted visual display units that allow users to be completely isolated from the physical world. Such an application operates in a specially constructed environment or laboratory, which makes it more expensive and time-consuming to construct. Aside this setback, it fully filters out interference from outside world as well as allowing oneself to focus entirely on the virtual environment.

Virtual Reality can take the advantage of interactive visualization techniques where the user can interact with the data to vary selection, classification, exaggeration and symbolisation for transforming data into meaningful information (Figure 1a). Such visualization can be classified under Desktop Virtual Reality. Virtual reality can take the form of an interface upon real world spatial information by taking the advantage of strong sense of immersion (Figure 1b). This can be classified under Semi-Immersive Virtual Reality. Virtual reality can also take the form of how the user can be fully and physically immersed in the model and responds as if operating in the real world (Figure 1c). Such an illustration can be classified under Fully Immersive Virtual Reality.

\section{Classification of Virtual Reality in Computer} Graphics using the S-P-I Model

Simulation is the process of imitating geographical reality in the computer environment. The processes of simulation can be geometrically static or 


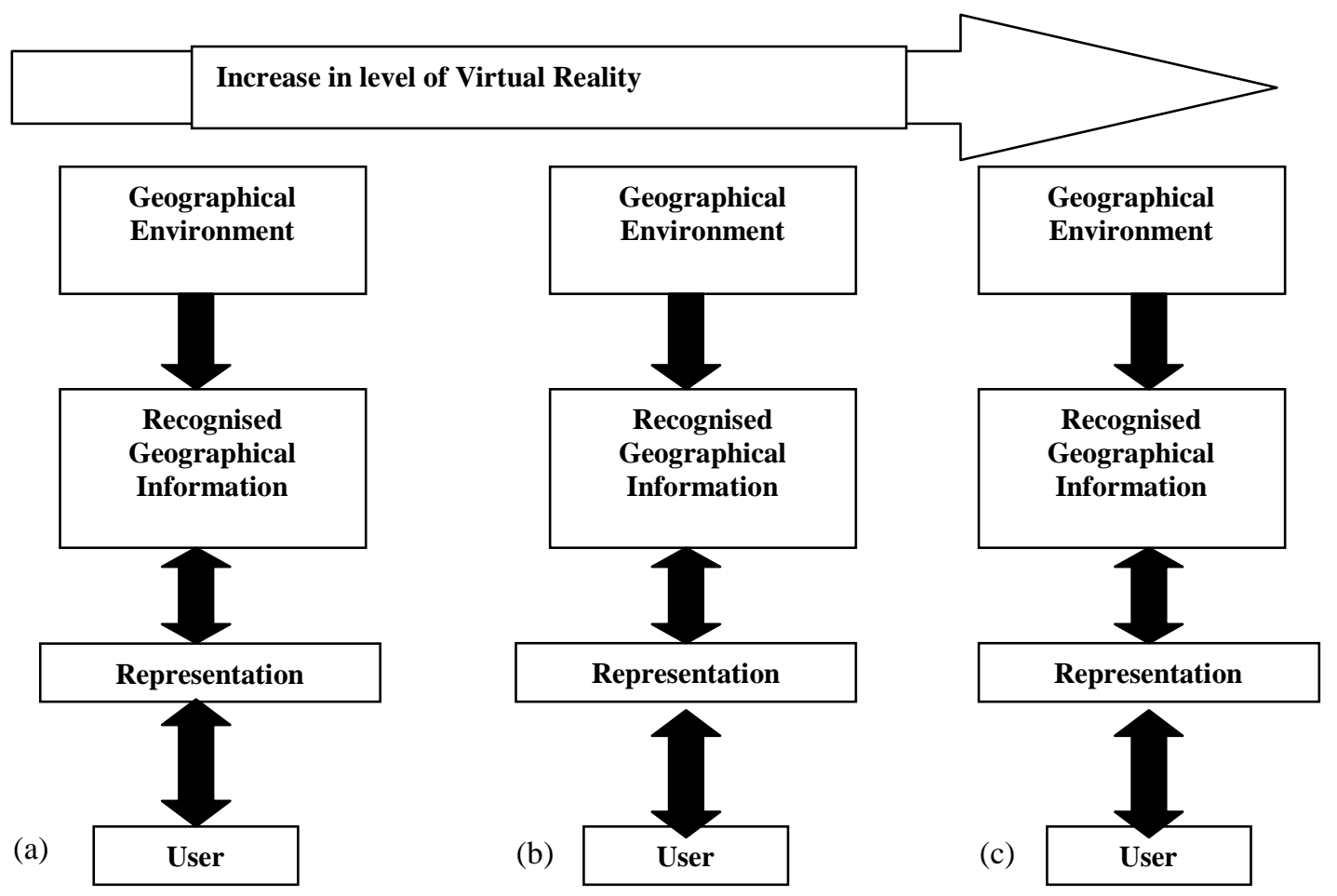

Fig. 1: Schematic illustration of VR regarded as a continuum based upon levels of interaction and the real world; (a) Desktop Virtual Reality where the user can interact with data to vary transformation; (b) Semi-Immersive Virtual Reality where the user is at least slightly immersed by the virtual environment; and (c) Fully Immersive Virtual Reality where the user is fully and physically immersed by the virtual environment (Adapted from Brodlie $e t$ al, 2002).

dynamic. A geometrically static simulation restricts motion whilst a geometrically dynamic simulation permits motion. In other words, a geometrically static simulation restricts visual analysis capabilities and a geometrically dynamic simulation gives the user the ability to change viewpoints. Dynamic geometric simulation has the potentiality in navigation and object manipulation than static geometric simulation. Presentation is the visualization of the simulated geographical reality on the computer. The visualization process can be a single event, sequence or real-time event. Interaction is the communication between human beings and simulated geographical reality on the computer. The communication can be interactive or immersive.

Virtual Reality can be placed in the Simulation Presentation Interaction (S-P-I) model system of classification to determine its Simulation (S), Presentation (P) and Interaction (I) in computer graphics. The S-P-I concept is purposefully designed for system classification in computer graphics (Encarnação et al, 1993). In the S-P-I model, Virtual Reality has the highest requirements of simulation, presentation and interaction (Fig. 2). 


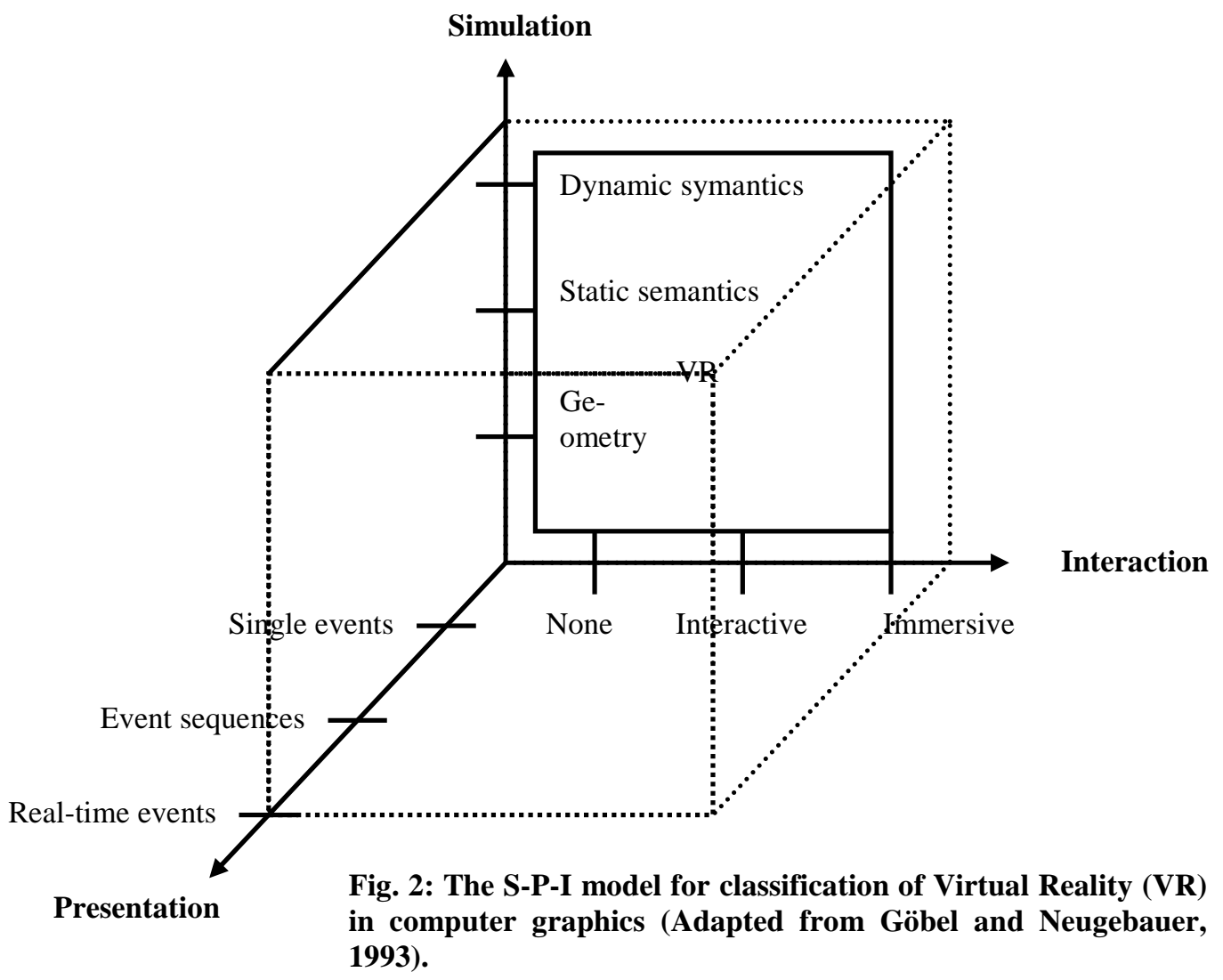

Simulation ranges from geometry to higher level dynamic entities like buildings, Presentation ranges from single events to real time events and Interaction ranges from non-interactions through interactive to immersive interactions (Figure 2).

In virtual reality, three essential components can be identified; that is, the simulation, presentation and interactions as indicated in the S-P-I model above. Simulation is the process whereby the behaviour of people and objects within the world are modelled. Presentation is the process of displaying the synthetic environment to the user either with immersive technology or simply on the desktop computer. Interaction is simply the human interaction (Brodlie and El-Khalili, 2002).
The authors explained further that there is always a communication within these three components, which results in a continuous process. That is, Simulation is the state in which the environment is fed into the presentation component and the interaction from the user is returned from the presentation component to the simulation component. Quaye-Ballard (2007) illustrated the S-P-I concept as follows: the simulation involves the conversion from 2D map to 3D model which moved from 2D to $2 \frac{1}{2} \mathrm{D}$ (using the extrusion technique) and lastly to $3 \mathrm{D}$ (using VRML export and photo-realistic texturing techniques); the Presentation involves the display of the environment in Cortona plug-in; and the Interaction involves the "walk", "fly", "study", "plan" and "turn" interactions embedded 
in the Cortona plug-in. Aside the classification of virtual reality, a distinction could be made between virtual reality and cartography.

\section{Virtual Reality and Cartography}

Virtual Reality could be said to be a subset of Cartography (Brodlie et al, 2002), whose capabilities could be used to increase the cartographic functionality in the computer environment (Berger et al., 1996). What makes virtual reality distinct or different from traditional cartography are the transformations in representing the world in each category (Figure 3). This can be seen in the nature of the relationship between the representation/user and map/map image in virtual reality and traditional cartography respectively.
Virtual reality can be identified as the creation of construct from reality when producing a virtual reality simulation (Figure 3a). The extended form of figure $3 \mathrm{a}$ is figure $3 \mathrm{~b}$, which shows the series of transformations involved in producing virtual reality. When the representation and user are interchanged with map and map image respectively, the framework for virtual reality will correspond to traditional cartographic process (Figure 3c). According to Brodlie et al (2002), the whole process illustrates the transformational view of cartography.

\section{Virtual Reality Modelling language (VRML)}

Based on the above discussions on virtual reality, it is interesting to mention that, virtual reality is

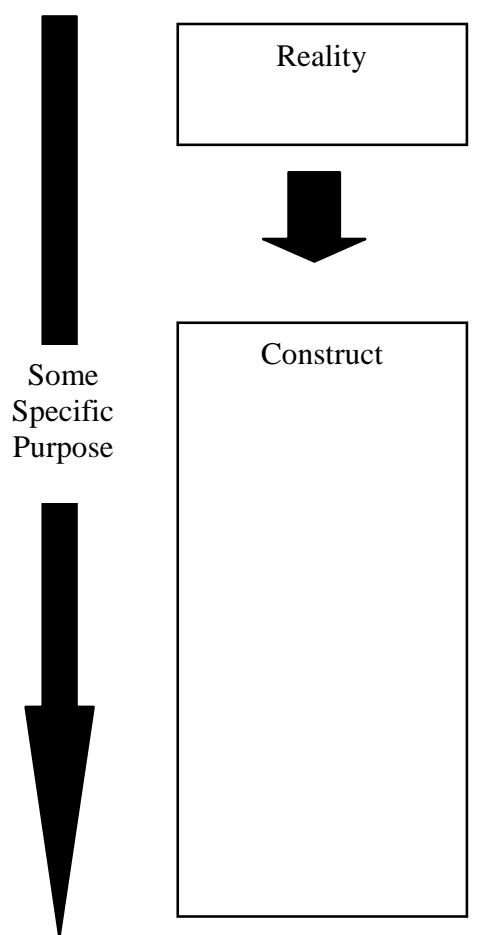

(a) VR (basic model)
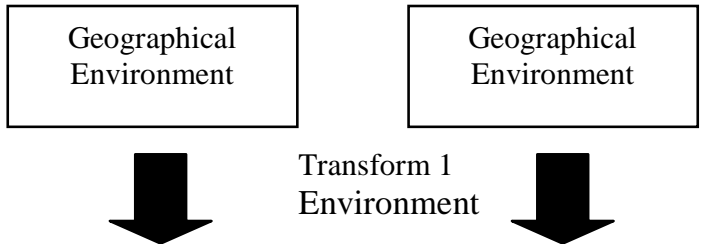
Environment
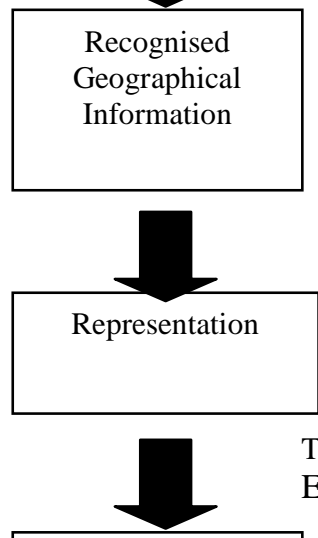

User

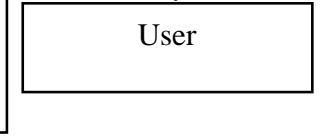

(b) VR (extended model)
Transform 1

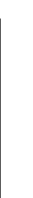

Transform 2

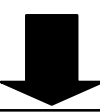

Recognised Geographical Information

Transform 3 Environment

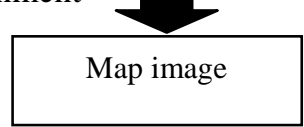

(c) A transformational view of cartography
Census

Ground Survey

Remote Sensing

Compilation

Selection

Classification

Simplification

Exaggeration

Symbolization

Reading

Analysis

Interpretation

Fig.3: Schematic representation of Virtual Reality and Cartography (Source: Brodlie et. al, 2002). 
not a method to imitate reality but rather to simulate aspects of reality as a sensual form of computation, which has called for major developments like VRML (Gillings and Goodrick, 1996). Desktop virtual reality, which offers view of a particular environment, uses VRML to create and manipulate these display environments (Rhyne, 1999). The original ideas and concepts behind VRML were not towards a common format for virtual reality, but rather an attempt to create three-dimensional interface to abstract information on the World Wide Web (Pesce et. al, 1994). VRML is a scene description language that describes the geometry and behaviour of a 3D scene or world (Crispen, 1998). To view a VRML world one needs a VRML browser, which is a program that reads a VRML file and displays the geometry, lighting, and animation as a 3D world. A VRML browser could be: a stand-alone application program, which can compile stand-alone applications that can view and manipulate VRML worlds. Examples are the Open World and the Open Inventor; a helper application, which has all the capabilities needed to view and manipulate VRML worlds. In this browser, whenever the web browser receives a link to a VRML world it will launch the helper application. An example is the VRWave; a plugin, which uses the facilities provided by web browsers to display VRML worlds in web browsers. Examples are Microsoft VRML for Microsoft Internet Explorer and the Parallel Graphic's Cortona 4.0 plug-in. A VRML world consists of one or more files conventionally with a 'wrl' suffix that together describe the geometry and attributes of objects in 3D scene (Lovett et al, 2002). These files are used to define shapes, textures, viewpoints and lights (Carey and Bell, 1997; Hartman and Wernecke, 1996).

With VRML it is possible to explore the virtual environment in a flexible and an interactive manner. Also, with VRML, it is possible to define specific viewpoints using the predefined tools on the control panel interface. As well as having the capabilities of ease of viewing with a standard World Wide Web (WWW) browser, limited soft- ware costs and potential for dissemination through the WWW (Lovett et al, 2002).

\section{Real life applications of Virtual Reality}

Some real life applications of virtual reality are explained below (Haklay, 2002):

- Urban and regional planning: Applications in this field range from attempts to produce large-scale urban models (Liggetti et al, 1995), to exploration of collaborative environments for design and planning (Dodge et $a l, 1997)$. These applications can be used to assess the visual impact of different planning schemes thereby enabling a group of planners to communicate through planning process.

- Environmental planning, modelling and impact assessment: Application in this field ranges from assessing the visual impact of planned forest (Buckley and Berry, 1997) to visualization of abstract phenomena like land contamination or air pollution (Bishop and Karadaglis, 1996).

- Scientific/geographic visualization: Applications in scientific/geographic visualization responses to the growing need for exploration and analysis of very large geo-spatial data sets.

- Military simulation and intelligence application: Military simulation, and more specifically flight simulation, is a major driving applications of virtual reality. One of the goals is to enable a 'virtual rehearsal' of future manoeuvres. Terrain modelling and visualization have a major role in these applications.

- Geographic Information Science: Virtual reality can be applied in Three Dimensional Geographic Information System (3D GIS) as well as the representation of data accuracy or the construction and representation of Digital Terrain Models (DTM).

- Archaeological modelling: Most of these applications in this area deal with the reconstruction of landscape and structures. The 
emphasis within this application is on visibility analysis and hypothesis validation (Gillings and Goodrick, 1996). For example, to reconstruct landscape and urban settings that do not exist, either 'no more' or 'not yet'. The 'no more' case occurs when an archaeologist wants to explore an ancient landscape in 3D whilst the 'not yet' case plays an important role in urban and environmental planning, especially for studies of visual impact of planned buildings and other construction projects such as roads, dams and bridges.

- Education: In the field of education, virtual reality course is being introduced in a number of disciplines. For example, some of the goals virtual reality in education is to enrich the learning process through visualization of distance or 'hard to reach' places and it is the multimedia possibilities of virtual reality that play an important role.

- Ecology: Applications in ecology are closely related to the discipline of environmental modelling. GIS and remote sensing are widely deployed in this field.

Virtual Reality models can be used in a bewildering context: That is, from analysing the effects of alcohol intake on the drivers of automobiles to training of surgeons and astronauts; from calming of nervous dental patients to creating utopian worlds within which individuals can socialise and gather (Brodlie and El-Khalili, 2002; Kitchin and Dodge, 2002).

The applications of virtual reality are inexhaustible. Virtual reality as a tool or approach can also be used by geographers to undertake investigations or present information in new and challenging ways (Brodlie et al, 2002).

A real life practical application of virtual reality in Cartographic Visualization is the visualization of land property for real estate agents (QuayeBallard, 2007). For such an application, the real estate agent as well as large private and public construction works can use the virtual map as an index to present all the properties of apartments and offices required for sale and maintenance.

\section{SUMMARY}

Virtual reality as a means of visualization helps users to explore the geographical space as if they are presenting it in the medium. One can develop an application using Virtual Reality to simulate real life situation without the need to visit the actual phenomenon in the field. Virtual reality is very important in analysing and visualizing scientific data because of the 3D and dynamic characteristics it provides. Virtual reality capabilities could be used to increase the cartographic functionality in the computer environment.

There is the need for 3D representation of our environment to which urban and regional planners, the environmentalist, the geographic information scientist, the military, the archaeologist, the ecologist, the educationist, the real estate agent etc. could interact. In this respect, virtual reality can be used to assess the visual impact of different visualization schemes thereby enabling meaningful and efficient decision making, monitoring and maintenance.

\section{REFERENCES}

Baker, M. P. and Wickens, C. D. (1992). Human Factors in Virtual Environments for the Visual Analysis of Scientific Data. http:// archive.ncsa.uiuc.edu/Vis/Publications/human Factors.html (Date accessed 22/10/2002, last modified 08/08/1998).

Berger, P., Meysembourg, P., Sales, J. and Johnston, C. (1996). Toward a virtual reality interface for landscape visualization. Proceedings of the Third International Conference/ Workshop on Integrating GIS and Environmental Modelling, January 21-25, 1996, Santa Fe, New Mexico.

Bishop, I. D. and Karadaglis, C. (1996). Combining GIS-based environmental modelling and visualization: another window on the model- 
ling process. Proceedings of the Third International Conference/Workshop on Integrating GIS and Environmental Modelling, January 21-25, 1996, Santa Fe, new Mexico, CD ROM.

Brodlie, K., Dykes, J., Gillings, M., Hakley, M. E., Kitchin, R. and Kraak, M. J. (2002). Geography in VR: Context. In Fisher, P. and Unwin, D. (eds). Virtual Reality in Geography. Taylor and Francis Publishers, London: 7-16

Brodlie, K. and El-Khalili (2002). Web-based virtual environments. In Fisher, P. and Unwin, D. (eds). Virtual Reality in Geography, Taylor and Francis Publishers, London: 3546.

Buckley, D. J. and Berry, J. K. (1997). Integrating advanced visualization techniques with ArcINFO for forest research and management. Proceedings of the 1997 ESRI UserConference Proceedings, July 8-11, 1997, San Diego, CA, CD ROM.

Burdea, G. and Coiffet, P. (1994). Virtual Reality Technology. New York: John Wiley.

Carey, R. and Bell, G. (1997). The Annotated VRML 2.0 Reference Manual. New York: Addison-Wiley.

Crispen, B. (1998). "VRML Works". http:// hiwaay.net/ crispen/vrml/faq/q1 (Date accessed 11/11/2002, last modified 11/06/1998).

Cronin, P. (1999). Report on the Applications of Virtual Reality Technology to Education. HCRC, University of Edinburgh. http:// www.cogsci.ed.ac.uk/ paulus/Work

Vranded/vr.htm (Date accessed 04/11/2002.Last modified 05/05/2000).

Diotin, R. and Kooy, J. (1995). Dynamic visualization of spatial data using virtual reality techniques. In Proceedings of the joint European Conference on Geographical Information. The Hague, Netherlands: 145-50
Dodge, M., Smith, A. and Doyle, S. (1997). Urban science. GIS Europe: 6, 10, 26-9

Encarnação, J. L., Astheimer, W., Felger, T., Frühauf, M., Göbel, M. and Müller, S. (1993). Graphics and Visualization: The essential features for the classification systems. In ICCG Proceedings. Bombay.

Fairbairn, D. and Parsey, S. (1996). The use of VRML for Cartographic Presentation. In ICA commission on visualization meeting, August 16-18, Delft, The Netherlands.

Fällman, D., Backman, A., and Holmlund, K. (1999). VR in Education: An Introduction to Multisensory Constructivist Learning Environments. Conference on University Pedagogy,Umeå University, Umeå. February 1819. Electronic Archive: http://daniel. fallman.org/resources/papers/Fallman VRIE.pdf (Date accessed 31/10/2002.Last modified 31/10/2002).

Fisher, P. and Unwin, D. (2002). Virtual Reality in Geography: An introduction. In Virtual Reality in Geography, Taylor and Francis Publishers, London: 1-4.

Gillings, M. and Goodrick G. (1996). Sensuous and reflective GIS exploring visualizations and VRML. http://intarch.ac.uk/journal/ issue1/gillings_toc.html (Date accessed 11/11/2002.Last modified 11/09/1996).

Göbel, M. and Neugebauer, J. (1993). The Virtual Reality Demonstration Centre. In Computer and Graphics 17(6): 627-631. Pergamon Press Ltd.

Haklay, M. E. (2002). Virtual reality and GIS. In Fisher, P. and Unwin, D. (eds). Virtual Reality in Geography. Taylor and Francis Publishers, London: 47-57.

Hartman, J. and Wernecke, J. (1996). The VRML 2.0 Handbook: Building Moving Worlds on the Wed. New York: Addison-Wiley.

Jacobson, R. (1994). "Virtual worlds capture spatial reality". GIS WORLD. December, 36(9) 
Keppell, M. and Macpherson, C. (1997). Is the Elephant Really There? - Virtual Reality in Education. http://dtls.cqu.edu.au/confsem/ derun/vr/contents.html (Date accessed $1 / 10 / 2002$, last modified 23/04/2002).

Kitchin, R. and Dodge, M. (2002). There's no there there. In Fisher, P. and Unwin, D. (eds). Virtual Reality in Geography, Taylor and Francis Publishers, London: 341-361.

Lovett, A., Kennaway, R., Sünnenberg, G., Cobb, D., Dolman, P., O'Riordan, T. and Arnold, D. (2002). Visualizing sustainable agricultural landscapes. In Fisher, P. and Unwin, D. (eds). Virtual Reality in Geography. Taylor and Francis Publishers, London: 102-130.

Liggetti, R., Friedman, S. and Jepson, W. (1995). Interactive design/decision making in virtual urban world: visual simulation and GIS. Proceedings of the 1995 ESRI User Conference, May 22-2, 1995, Palm Springs. CA, CD ROM.

Ogao, P. J. (1997). Visualization of 3-D Spatial Data Using Virtual Reality Model Language (VRML). MSc Thesis ITC, Enschede, The Netherlands.
Online Dictionary.com (2006). "Dictionary.com" Electronic Archive: http://www. dictionary.com/search?q=real\%20estate\%20agent (Date accessed 23/08/2006, last modified 23/08/2006)

Pesce, M. D., Kennard, P. and Parisi, A. S. (1994). Cyberspace. Proceedings of the First International Conference on the World Wide Web, May 25-26, 1994, CERN, Geneva.

Quaye-Ballard, J. A. (2007). The use of Virtual Reality in Visualizing Land Property. Journal of Science and Technology (JUST), Kumasi, Ghana, 27(1), 102-108.

Rhyne, T. M. (1999). A commentary on GeoVRML: A tool for 3D representation of georeferenced data on the web. International Journal of Geographic Information Science 13(4): 439-443.

Stoter, J. (2002). "3D Cadastres: State-of-the art". GIM International Magazine 16(2).

Verbree, E., Maren, G. V., Germs, R., Jansen, F. and Kraak, M. J. (1999). Interaction in virtual world views - linking 3D GIS with VR. International Journal of Geographical Information Science. 13(4): 385-396. 